\title{
Enantioselective PCCP Brønsted acid-catalyzed aza-Piancatelli rearrangement
}

\author{
Gabrielle R. Hammersley, Meghan F. Nichol, Helena C. Steffens, Jose M. Delgado, \\ Gesine K. Veits and Javier Read de Alaniz*
}

\author{
Letter \\ Address: \\ Department of Chemistry and Biochemistry, University of California \\ Santa Barbara, Santa Barbara, CA 93106-9510, USA \\ Email: \\ Javier Read de Alaniz* - javier@chem.ucsb.edu \\ * Corresponding author \\ Keywords: \\ aza-Piancatelli; Brønsted acid; cyclopentane; furylcarbinols; PCCP
}

\author{
Beilstein J. Org. Chem. 2019, 15, 1569-1574. \\ doi:10.3762/bjoc. 15.160 \\ Received: 05 April 2019 \\ Accepted: 03 July 2019 \\ Published: 12 July 2019 \\ This article is part of the thematic issue "Reactive intermediates - \\ carbocations". \\ Guest Editor: S. R. Hare
}

(C) 2019 Hammersley et al.; licensee Beilstein-Institut.

License and terms: see end of document.

\begin{abstract}
An enantioselective aza-Piancatelli rearrangement has been developed using a chiral Brønsted acid based on pentacarboxycyclopentadiene (PCCP). This reaction provides rapid access to valuable chiral 4-amino-2-cyclopentenone building blocks from readily available starting material and is operationally simple.
\end{abstract}

\section{Introduction}

The discovery of a wide range of cyclopentane containing natural products $[1,2]$ and biologically active molecules such as palau'amine [3,4], agelastatin A [5-7], pactamycin [8-10], and aristeromycin [11,12], has created a demand for new methodologies to construct this privileged scaffold. The aza-Piancatelli reaction has recently emerged as a particularly attractive method to access densely functionalized cyclopentene cores bearing nitrogen substituents directly from readily available 2-furylcarbinols [13-15]. Inspired by Piancatelli's original work in 1976 [16], our group has developed both the inter- and intramolecular aza-Piancatelli reaction using commercially available dysprosium trifluoromethanesulfonate $\left(\mathrm{Dy}(\mathrm{OTf})_{3}\right)$ as a catalyst with a range of nitrogen nucleophiles [17-23]. The range of catalytic systems facilitating this reaction has been extended to include other Brønsted and Lewis acids, such as phosphomolybdic acid (PMA) [24], $\mathrm{Ca}\left(\mathrm{NTf}_{2}\right)_{2}$ [25], $\mathrm{In}(\mathrm{OTf})_{3}$ [26], $\mathrm{La}(\mathrm{OTf})_{3}$ [27], and $\mathrm{BF}_{3} \cdot \mathrm{OEt}_{2}$ [28], as well as other nucleophiles [29-31].

In all cases examined, the products of the aza-Piancatelli reaction have a trans relationship between the $\mathrm{C} 4$ and $\mathrm{C} 5$ substituents [13-15]. It is believed that the $4 \pi$ conrotatory electrocyclization step that converts the pentadienyl cation 5 into the corresponding cyclopentenone adduct $\mathbf{6}$ is responsible for control- 
ling the relative diastereoselectivity in this cascade rearrangement (Figure 1). Analogous to the Nazarov cyclization, controlling the absolute stereochemistry can be achieved by governing the direction of the conrotatory electrocyclization, clockwise vs counterclockwise [32-34]. Despite the direct relationship to the asymmetric Nazarov cyclization, however, it was not until 2016 that the first asymmetric aza-Piancatelli reaction was described. To control the absolute stereochemistry of the aza-Piancatelli rearrangement, Rueping [35], Sun [36], and Patil [37] independently demonstrated that chiral phosphoric acids can be used as an enantioselectivity-inducing element capable of controlling the clockwise or counterclockwise conrotation of the key $4 \pi$ electrocyclization step.

Although the utility of these asymmetric catalytic systems is unquestionable, the ability to identify the optimal catalyst is not straightforward. In each case, extensive optimization of the reaction conditions was required to achieve high enantioselectivity and good yield, with small variations to the catalyst architecture or solvent having dramatic effects on enantioselectivity or yield. Because of these challenges and our group's ongoing interest in further developing the aza-Piancatelli reaction, we sought to identify other asymmetric catalytic systems capable of controlling the absolute stereochemistry. To this end, we envisioned that the chiral pentacarboxycyclopentadiene (PCCP) Brønsted acid catalyst (8) recently developed by the Lambert lab might be suitable (Figure 1) [38]. First, the $\mathrm{p} K_{\mathrm{a}}$ values measured in acetonitrile $(\mathrm{MeCN})$ are lower than chiral phosphoric acids (Brønsted acid $\mathrm{p} K_{\mathrm{a}}=8.85$ vs chiral phosphoric acids $\left.\mathrm{p} K_{\mathrm{a}}=12-14\right)$ [38]. Given the enhanced acidity, we reasoned that this type of chiral Brønsted acid catalyst could facilitate the dehydration reaction of the furylcarbinol to generate the oxocarbenium intermediate. Second, by analogy to asymmetric induction in aza-Piancatelli reactions with chiral phosphoric acids,

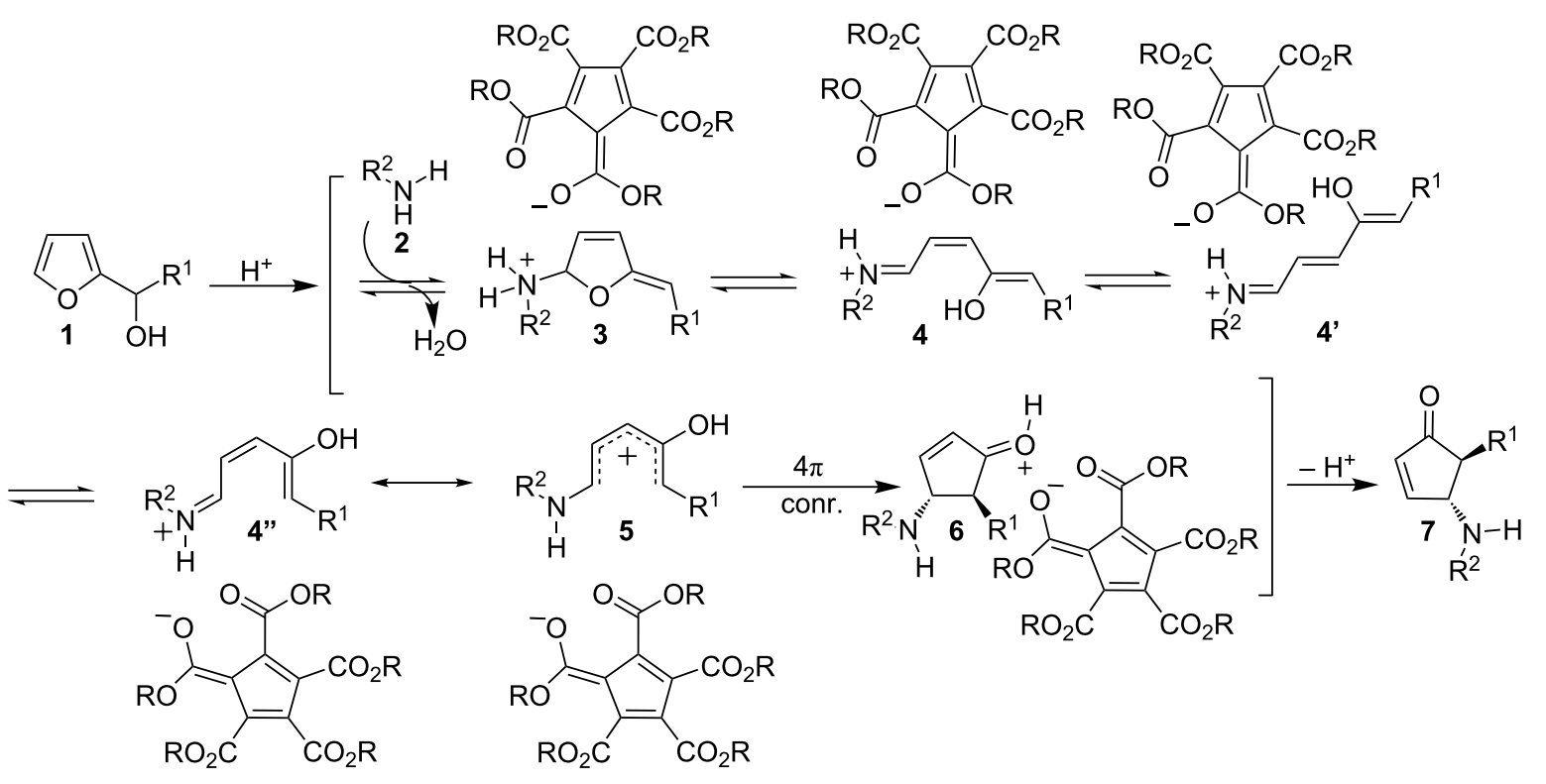

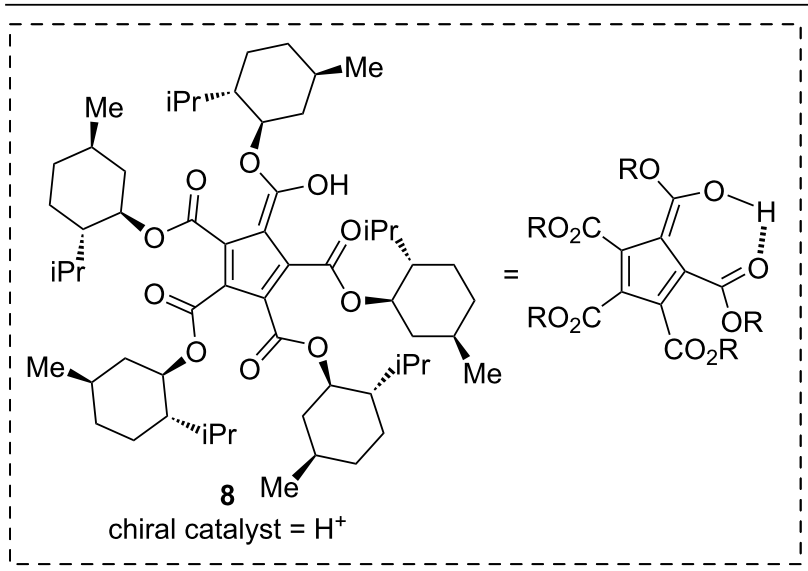


where enantioselectivity has generally been achieved by strategically installing bulky groups on the hydrogen-bonding catalysts, we hypothesized that a PCCP-derived catalyst could be used. It is proposed that the chiral anion moieties serve to interact with the key intermediate 5 during the enantiodetermining electrocyclization step [35-37]. A tentative mechanistic hypothesis for the asymmetric aza-Piancatelli is shown in Figure 1. Finally, this new catalyst can be produced inexpensively and on scale, features that are attractive for developing a wide range of asymmetric transformations.

\section{Results and Discussion}

Herein, we describe our initial efforts in this area using chiral Brønsted acid catalyst $\mathbf{8}$. Our investigations began by examining the reaction of para-iodoaniline (2a) with furylcarbinol 1a in dichloromethane (DCM) in the presence of $5 \mathrm{~mol} \%$ chiral Brønsted acid 8 (Table 1). We were pleased to find that $\mathbf{8}$ catalyzed the desired asymmetric transformation at $40{ }^{\circ} \mathrm{C}$, affording 4-aminocyclopentenone $7 \mathbf{a}$ in $78 \%$ yield and a moderate $65 \%$ ee. At lower temperatures $\left(30^{\circ} \mathrm{C}\right.$ and $\left.23{ }^{\circ} \mathrm{C}(\mathrm{rt})\right)$ the selectivity increased to $73 \%$ and $78 \%$ ee, respectively. For consistency the optimization studies were all allowed to run for $48 \mathrm{~h}$ with higher temperatures being more efficient (Table 1, entries 1-3). Importantly, the catalytic activity did not diminish with extended reaction time and the yield of the room temperature reaction could be increased to $70 \%$ by extending the reaction time from $48 \mathrm{~h}$ to $120 \mathrm{~h}$ (Table 1, entry 4). The asymmetric reaction was found to be most effective at $23{ }^{\circ} \mathrm{C}$ (Table 1 , entries 3 and 4). Unfortunately, attempts to lower the tempera- ture further resulted in exceedingly long reaction times, greater than 5 days, and thus were not pursued. Next the effects of aromatic and halogenated solvents were evaluated (Table 1, entries 5-7), with DCM proving optimal. We developed the reaction using $5 \mathrm{~mol} \%$ catalyst in DCM at $23{ }^{\circ} \mathrm{C}$ as the optimized reaction conditions.

With optimized reaction conditions in hand, we set out to explore the scope and limitations of the asymmetric reaction (Scheme 1). Initially, we examined the reaction of various anilines with furylcarbinol 1a. Scheme 1 summarizes the results obtained with ortho-, meta-, and para-substituted aniline derivatives. The reaction of anilines bearing an electron-withdrawing group at the para-position afforded the optimal balance between efficiency and enantioselectivity. Consistent with Rueping's work [35], ortho-aminobenzoic acid, which contains an additional hydrogen bond group afforded the best selectivity (7k). To simplify the purification process, all acid products were transformed into the corresponding methyl ester in situ using (trimethylsilyl)diazomethane. A slight drop in enantioselectivity is observed when the benzoic acid group was moved to the meta-position or when using the methyl ester ( $\mathbf{7 i}$ and $\mathbf{7 j}$ ). The absolute stereochemistry of the product $7 \mathbf{k}$ was assigned by comparison to literature [35] and the other products were assigned by analogy.

To further expand the substrate scope, we investigated the effects on both reactivity and enantioselectivity when substituted furylcarbinols were used with either para-iodoaniline (2a)

Table 1: Initial optimization studies.

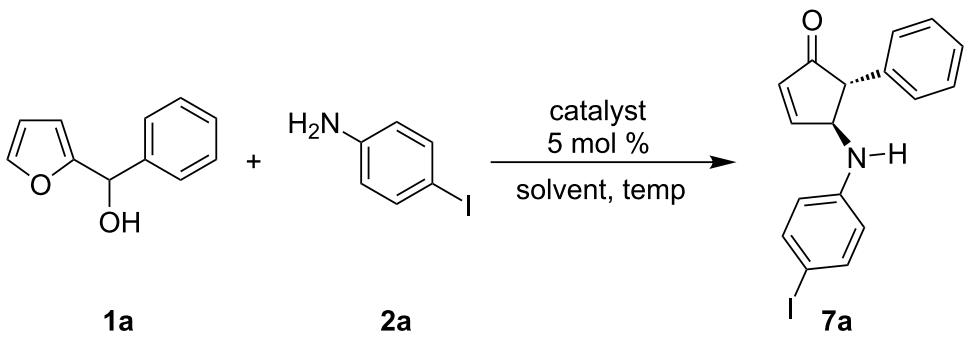

\begin{tabular}{lllll}
\hline Entry & Solvent & Temp $\left({ }^{\circ} \mathrm{C}\right)$ & ee (\%) & Yield (\%) \\
\hline 1 & DCM & 40 & 65 & 78 \\
2 & DCM & 30 & 73 & 46 \\
3 & DCM & $\mathrm{rt}$ & 78 & 26 \\
$4^{\mathrm{a}}$ & $\mathrm{DCM}$ & $\mathrm{rt}$ & 75 & 70 \\
5 & DCE & $\mathrm{rt}$ & 68 & 23 \\
6 & fluorobenzene & $\mathrm{rt}$ & 76 & 20 \\
7 & toluene & $\mathrm{rt}$ & 75 & 12 \\
\hline
\end{tabular}

aThis reaction was run for 5 days whereas the rest of the reactions were run for 2 days. Dichloromethane (DCM), 1,2-dichloroethane (DCE), room temperature (rt). 
<smiles>OC(c1ccccc1)c1ccco1</smiles>

1a<smiles>[R]c1cccc(N)c1</smiles>

2a-k
$5 \mathrm{~mol} \%$ cat 8

DCM, $23^{\circ} \mathrm{C}$

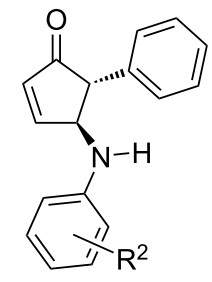

7a-k

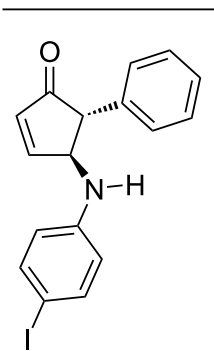

$7 a$ $70 \%$ yield $75 \%$ ee

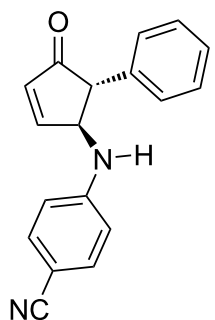

$7 \mathrm{~b}$

$50 \%$ yield $71 \%$ ee

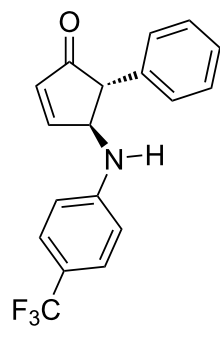

7c $64 \%$ yield $76 \%$ ee<smiles>CC(=O)c1ccc(NC2C=CC(=O)C2c2ccccc2)cc1</smiles>

7d $71 \%$ yield $73 \%$ ee<smiles>CC(=O)c1ccc(NC2C=CC(=O)[C@H]2c2ccccc2)cc1</smiles>

$7 e$

$65 \%$ yield $76 \%$ ee

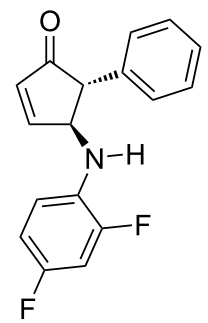

$7 f$

$65 \%$ yield $63 \%$ ee

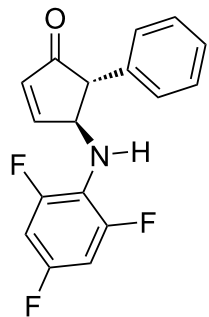

$7 \mathrm{~g}$ $53 \%$ yield $61 \%$ ee

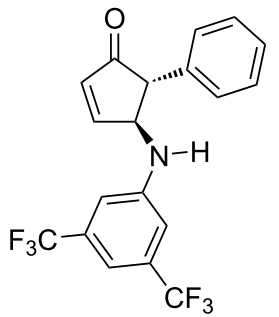

$7 \mathrm{~h}$

$58 \%$<smiles>CC(=O)c1cccc(NC2C=CC(=O)[C@H]2c2ccccc2)c1</smiles>

$7 i^{*}$

$19 \%$ yield

$74 \%$ ee

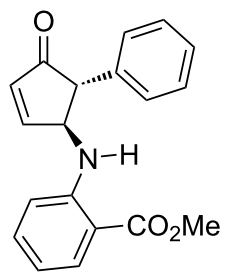

$7 \mathrm{j}$

$44 \%$ yield

$80 \%$ ee<smiles>CCOC(=O)c1ccccc1NC1C=CC(=O)[C@H]1c1ccccc1</smiles>

$7 k^{*}$

$59 \%$ yield

$84 \%$ ee

Scheme 1: Asymmetric aza-Piancatelli rearrangement with a range of substituted anilines. *To simplify the purification process, carboxylic acids were transformed in situ into the corresponding methyl ester using (trimethylsilyl)diazomethane.

or ortho-aminobenzoic acid (2k, Scheme 2). In every case examined, the ortho-aminobenzoic acid gave higher selectivity compared to the corresponding para-iodoaniline, which supports the importance of the additional hydrogen bonding capability of the carboxylic acid group. In contrast, with the exception of $\mathbf{7 p}$ and $\mathbf{7 q}$, a lower yield was obtained when orthoaminobenzoic acid was used. Presumably, this decrease in efficiency is due to the increased steric bulk on the aniline, which slows the initial nucleophilic attack on the furan ring required to initiate the cascade sequence. This highlights that a balance between nucleophilicity and hydrogen bond capabilities are required to obtain an efficient and selective reaction. Compared to the rearrangement of furylcarbinol 1a, sterically bulky aryl groups attached to the furylcarbinol resulted in significantly diminished enantioselectivity (7l and $\mathbf{7} \mathbf{m}$ ). In contrast, placing a substituent at either the meta- or para-position showed no effect on the selectivity when compared to an unsubstituted phenyl group. For example, 1a afforded the desired product in $75 \%$ ee, while $1 \mathbf{n}$ and $1 \mathbf{p}$ afforded the cyclopentenone product in $76 \%$ ee and $75 \%$ ee, respectively. In general, the enantioselectivity of the reactions with para-iodoaniline and ortho-aminobenzoic acid behaved similarly, with the selectivity being influenced most obviously by changes in the furylcarbinol. However, a dramatic difference in selectivity was observed when employing a tertiary furylcarbinol ( $7 \mathbf{r}$ and $\mathbf{7 s}$ ). In this case, orthoaminobenzoic acid resulted in the desired product with good enantioselectivity ( $72 \%$ ee), while para-iodoaniline only gave a modest $41 \%$ ee. The exact nature for the decrease in enantioselectivity in this case with para-iodoaniline is not clear.

\section{Conclusion}

In summary, we have developed an efficient asymmetric azaPiancatelli rearrangement that constructs a carbon-carbon bond plus a carbon-nitrogen bond and controls the absolute stereochemistry of the two stereocenters, through control of the direction of conrotation, in a single operation. This strategy offers a 


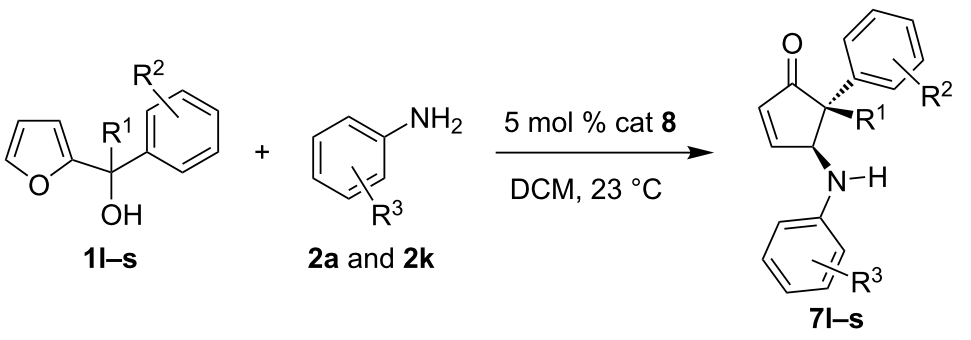

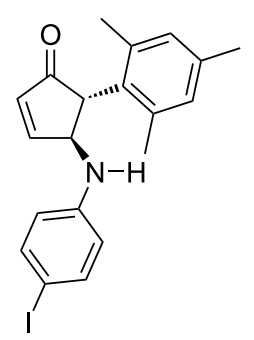

71

$65 \%$ yield $17 \%$ ee<smiles>CC(=O)c1ccccc1N(C)[C@@H]1C=CC(=O)[C@H]1c1c(C)cc(C)cc1C</smiles>

$7 \mathrm{~m}^{*}$

$28 \%$ yield $28 \%$ ee

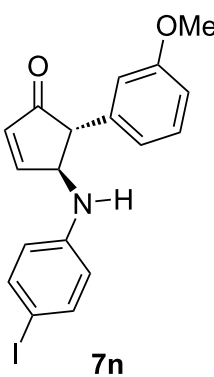

$50 \%$ yield

$76 \%$ ee

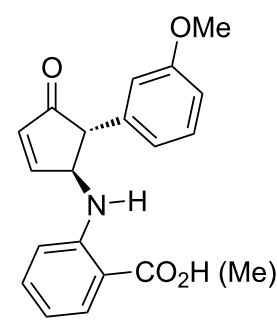

7o*

$36 \%$ yield $87 \%$ ee<smiles>COc1ccc([C@H]2C(=O)C=CC2Nc2ccc(I)cc2)cc1</smiles>

$7 p$

$17 \%$ yield $75 \%$ ee<smiles>COc1ccc([C@H]2C(=O)C=CC2Nc2ccccc2C(C)=O)cc1</smiles>

$7 q^{*}$

$52 \%$ yield

$86 \%$ ee

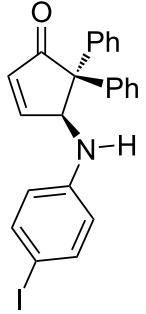

$7 r$

$77 \%$ yield

$41 \%$ ee<smiles>CCOC(=O)c1ccccc1NC1C=CC(=O)C1(c1ccccc1)c1ccccc1</smiles>

$7 s^{*}$

$26 \%$ yield

$72 \%$ ee

Scheme 2: Asymmetric aza-Piancatelli rearrangement with a range of substituted furylcarbinols. *To simplify the purification process, carboxylic acids were transformed in situ into the corresponding methyl ester using (trimethylsilyl)diazomethane.

practical alternative to using chiral phosphoric acids and demonstrates that chiral PCCP-based Brønsted acid catalysts can be used to control the absolute stereochemistry of the azaPiancatelli rearrangement. The PCCP chiral Brønsted acid catalyzed reaction shows good substrate scope and proceeds well with a range of aniline and furylcarbinol derivatives. The ability to control the absolute stereochemistry of the $4 \pi$ electrocylization using an inexpensive and easy to prepare chiral Brønsted acid catalyst holds tremendous promise for the aza-Piancatelli and related rearrangements.

\section{Experimental}

General procedure for the rearrangement: Furylcarbinol 1 and aniline 2 were dissolved in DCM. At $23{ }^{\circ} \mathrm{C}, 5 \mathrm{~mol} \%$ of the catalyst $\mathbf{8}$ was added to the reaction mixture and the reaction mixture was stirred for 5 days. The reaction was then quenched with saturated aqueous sodium bicarbonate and extracted with DCM $(3 \times 5 \mathrm{~mL})$. The combined organic layers were dried over
$\mathrm{MgSO}_{4}$, filtered, and concentrated in vacuo. The residue was then purified by column chromatography to afford cyclopentenone 7.

\section{Supporting Information}

\section{Supporting Information File 1}

Experimental part and copies of NMR spectra.

[https://www.beilstein-journals.org/bjoc/content/ supplementary/1860-5397-15-160-S1.pdf]

\section{Acknowledgements}

This work was supported by the National Science Foundation under a Career Award CHE-1057180. The research made use of NMR instrumentation that was supported by an NIH Shared Instrumentation Grant (1S10OD012077-01A1). M. F. N. thanks the Mellichamp Academic Initiative in Sustainability for a 
fellowship in support of this research. J. M. D. thanks the McNair Foundation for support.

\section{ORCID ${ }^{\circledR}$ iDs}

Gabrielle R. Hammersley - https://orcid.org/0000-0002-4391-6954 Meghan F. Nichol - https://orcid.org/0000-0002-3607-6002 Jose M. Delgado - https://orcid.org/0000-0003-3292-0584 Javier Read de Alaniz - https://orcid.org/0000-0003-2770-9477

\section{References}

1. Liu, G.; Shirley, M. E.; Van, K. N.; McFarlin, R. L.; Romo, D. Nat. Chem. 2013, 5, 1049-1057. doi:10.1038/nchem.1788

2. Heasley, B. Curr. Org. Chem. 2014, 18, 641-686. doi:10.2174/13852728113176660150

3. Köck, M.; Grube, A.; Seiple, I. B.; Baran, P. S. Angew. Chem., Int. Ed. 2007, 46, 6586-6594. doi:10.1002/anie.200701798

4. Seiple, I. B.; Su, S.; Young, I. S.; Lewis, C. A.; Yamaguchi, J.; Baran, P. S. Angew. Chem., Int. Ed. 2010, 49, 1095-1098. doi:10.1002/anie.200907112

5. Trost, B. M.; Dong, G. J. Am. Chem. Soc. 2006, 128, 6054-6055. doi:10.1021/ja061105q

6. Yoshimitsu, T.; Ino, T.; Tanaka, T. Org. Lett. 2008, 10, 5457-5460. doi:10.1021/ol802225g

7. Duspara, P. A.; Batey, R. A. Angew. Chem., Int. Ed. 2013, 52, 10862-10866. doi:10.1002/anie.201304759

8. Hanessian, S.; Vakiti, R. R.; Dorich, S.; Banerjee, S.; Lecomte, F.; DelValle, J. R.; Zhang, J.; Deschênes-Simard, B.

Angew. Chem., Int. Ed. 2011, 50, 3497-3500. doi:10.1002/anie.201008079

9. Malinowski, J. T.; Sharpe, R. J.; Johnson, J. S. Science 2013, 340, 180-182. doi:10.1126/science.1234756

10. Sharpe, R. J.; Malinowski, J. T.; Johnson, J. S. J. Am. Chem. Soc. 2013, 135, 17990-17998. doi:10.1021/ja409944u

11. Trost, B. M.; Kuo, G. H.; Benneche, T. J. Am. Chem. Soc. 1988, 110 , 621-622. doi:10.1021/ja00210a064

12. Mieczkowski, A.; Roy, V.; Agrofoglio, L. A. Chem. Rev. 2010, 110 , 1828-1856. doi:10.1021/cr900329y

13. Piutti, C.; Quartieri, F. Molecules 2013, 18, 12290-12312. doi:10.3390/molecules181012290

14. Wenz, D. R.; Read de Alaniz, J. Eur. J. Org. Chem. 2015, 23-37. doi:10.1002/ejoc.201402825

15. Gomes, R. F. A.; Coelho, J. A. S.; Afonso, C. A. M. Chem. - Eur. J. 2018, 24, 9170-9186. doi:10.1002/chem.201705851

16. Piancatelli, G.; Scettri, A.; Barbadoro, S. Tetrahedron Lett. 1976, 17, 3555-3558. doi:10.1016/s0040-4039(00)71357-8

17. Veits, G. K.; Wenz, D. R.; Read de Alaniz, J. Angew. Chem., Int. Ed. 2010, 49, 9484-9487. doi:10.1002/anie.201005131

18. Palmer, L. I.; Read de Alaniz, J. Angew. Chem., Int. Ed. 2011, 50, 7167-7170. doi:10.1002/anie.201102102

19. Palmer, L. I.; Read de Alaniz, J. Org. Lett. 2013, 15, 476-479. doi:10.1021/ol303263q

20. Yu, D.; Thai, V. T.; Palmer, L. I.; Veits, G. K.; Cook, J. E.; Read de Alaniz, J.; Hein, J. E. J. Org. Chem. 2013, 78, 12784-12789. doi:10.1021/j0402155b

21. Read de Alaniz, J.; Palmer, L. Synlett 2014, 25, 8-11. doi:10.1055/s-0033-1340157

22. Fisher, D.; Palmer, L. I.; Cook, J. E.; Davis, J. E.; Read de Alaniz, J. Tetrahedron 2014, 70, 4105-4110. doi:10.1016/j.tet.2014.03.007
23. Veits, G. K.; Wenz, D. R.; Palmer, L. I.; St. Amant, A. H.; Hein, J. E.; Read de Alaniz, J. Org. Biomol. Chem. 2015, 13, 8465-8469. doi:10.1039/c5ob00944h

24. Subba Reddy, B. V.; Narasimhulu, G.; Subba Lakshumma, P.; Vikram Reddy, Y.; Yadav, J. S. Tetrahedron Lett. 2012, 53, 1776-1779. doi:10.1016/j.tetlet.2012.01.115

25. Lebœuf, D.; Schulz, E.; Gandon, V. Org. Lett. 2014, 16, 6464-6467. doi:10.1021/ol5032987

26. Reddy, B. V. S.; Reddy, Y. V.; Lakshumma, P. S.; Narasimhulu, G.; Yadav, J. S.; Sridhar, B.; Reddy, P. P.; Kunwar, A. C. RSC Adv. 2012, 2, 10661-10666. doi:10.1039/c2ra21591h

27. Liu, J.; Shen, Q.; Yu, J.; Zhu, M.; Han, J.; Wang, L. Eur. J. Org. Chem. 2012, 6933-6939. doi:10.1002/ejoc.201200962

28. Nunes, J. P. M.; Afonso, C. A. M.; Caddick, S. RSC Adv. 2013, 3 , 14975. doi:10.1039/c3ra42663g

29. Yin, B.; Huang, L.; Wang, X.; Liu, J.; Jiang, H. Adv. Synth. Catal. 2013, 355, 370-376. doi:10.1002/adsc.201200850

30. Wang, C.; Dong, C.; Kong, L.; Li, Y.; Li, Y. Chem. Commun. 2014, 50, 2164-2166. doi:10.1039/c3cc49191a

31. Xu, J.; Luo, Y.; Xu, H.; Chen, Z.; Miao, M.; Ren, H. J. Org. Chem. 2017, 82, 3561-3570. doi:10.1021/acs.joc.7b00090

32. Tius, M. A. Eur. J. Org. Chem. 2005, 2193-2206. doi:10.1002/ejoc.200500005

33. Frontier, A. J.; Collison, C. Tetrahedron 2005, 61, 7577-7606. doi:10.1016/j.tet.2005.05.019

34. Shimada, N.; Stewart, C.; Tius, M. A. Tetrahedron 2011, 67, 5851-5870. doi:10.1016/j.tet.2011.05.062

35. Cai, Y.; Tang, Y.; Atodiresei, I.; Rueping, M. Angew. Chem., Int. Ed. 2016, 55, 14126-14130. doi:10.1002/anie.201608023

36. Li, H.; Tong, R.; Sun, J. Angew. Chem., Int. Ed. 2016, 55 , 15125-15128. doi:10.1002/anie.201607714

37. Gade, A. B.; Patil, N. T. Synlett 2017, 28, 1096-1100. doi:10.1055/s-0036-1558952

38. Gheewala, C. D.; Collins, B. E.; Lambert, T. H. Science 2016, 351, 961-965. doi:10.1126/science.aad0591

\section{License and Terms}

This is an Open Access article under the terms of the Creative Commons Attribution License (http://creativecommons.org/licenses/by/4.0). Please note that the reuse, redistribution and reproduction in particular requires that the authors and source are credited.

The license is subject to the Beilstein Journal of Organic Chemistry terms and conditions:

(https://www.beilstein-journals.org/bjoc)

The definitive version of this article is the electronic one which can be found at: doi: $10.3762 /$ bjoc. 15.160 